\title{
Cardiac and renal function in patients with type 2 diabetes who have chronic kidney disease: potential effects of bardoxolone methyl
}

This article was published in the following Dove Press journal:

Drug Design, Development and Therapy

16 June 2012

Number of times this article has been viewed

\author{
Peter A McCullough \\ Sajid Ali \\ St John Hospital and Medical Center, \\ Providence Hospital and Medical \\ Centers, Departments of Medicine, \\ St John Providence Health System, \\ Detroit, MI, USA
}

\begin{abstract}
The intracellular and tissue balance of oxidant and antioxidant forces is a potential therapeutic target for a variety of agents in the treatment of complications due to chronic disease including diabetes mellitus and hypertension. There are a myriad of processes controlled at the level of genes, transcription factors, and protein messages that work to control the normal use of oxidative reactions within cells. Loss of control of these processes may lead to reversible dysfunction in many cell lines including the podocyte, renal tubular cells, and cardiac myocytes. Bardoxolone methyl is a novel nuclear regulator factor (Nrf-2) activator which works to tip the balance of effects towards antioxidation and as an observation made serendipitously, improves renal filtration function in humans after approximately 12 weeks of therapy. The improvement in estimated glomerular filtration can be up to $30 \%$ in those with stage 3 and 4 chronic kidney disease. However, experimental evidence suggests there may be a consequence of relative hyperfiltration in diseased kidneys as well as potential adverse effects on skeletal and cardiac myocytes. Only large, prospective randomized trials with carefully collected and adjudicated clinical outcomes will inform the research community on the therapeutic risks and benefits of this important new agent.
\end{abstract}

Keywords: bardoxolone methyl, chronic kidney disease, diabetes mellitus, glomerular filtration, cardiomyocyte, oxidative stress

\section{Introduction}

The pandemic of type 2 diabetes mellitus (T2DM) and cardiometabolic risk has led to concerns over the future population burden of chronic heart and kidney disease. Because of the very tight relationships between heart and kidney regulation, function, and codependence, changes in the operational parameters of one organ system affect the other on a multitude of levels. There has been considerable progress in the areas of preventive cardiology including smoking cessation, lipid reduction, and blood pressure and glycemic control which have resulted in reductions of myocardial infarction and heart failure; however, patients with chronic kidney disease (CKD) remain as a concern given the narrow therapeutic window for most management strategies including procedures, devices, and medications. ${ }^{1}$ For example, in patients admitted with acute decompensated heart failure, approximately $25 \%$ develop type 1 cardiorenal syndrome and a sequential decline in renal filtration function which prolongs hospitalization, complicates management, and in some cases, leads to death. ${ }^{2}$ Conversely, in patients with CKD, death from cardiac causes is a larger clinical threat than the development of end-stage renal disease requiring renal replacement therapy. ${ }^{3}$ While conventional cardiac and renal therapeutic targets are of principal concern to
Correspondence: Peter A McCulloug Department of Medicine, Cardiology Section, St John Providence Health System, Providence Park Heart Institute, 4760 I Grand River Avenue, Suite BI25, Novi, MI, USA, 48374

Tel +2484655485

Fax +2484655486

Email peteramccullough@gmail.com 
practitioners today, the search for common cellular processes that may serve as therapeutic targets has led to promising new approaches. ${ }^{4}$ Thus, the interest and enthusiasm for new therapeutic agents that can favorably affect the function of one or both organs and lead to considerable improvement in measurable clinical outcomes is piqued in this renascent era of cardiorenal medicine. ${ }^{5}$

\section{The glomerular filtration barrier}

The filtration barrier within the renal glomerulus has been the subject of investigation for decades. As blood moves from the renal arterioles into the preglomerular afferents and the tortuous glomerular tufts, a critical hydrostatic and oncotic pressure head is maintained. ${ }^{6}$ The filtration barrier from endovascular to urinary that is traversed by water and solute includes the negatively charged endothelial glycocalyx, fenestrated endothelium, gelatinous basement membrane, and slit diaphragm created by the foot processes of podocytes. Pathobiologic changes occur at the level of the endothelium and the podocyte in all patients with T2DM that lead to the eventual decline in glomerular filtration function and loss of blood proteins in the urine; which in turn, accelerate disease progression in other nephron units and in aggregate contribute to the global development of diabetic CKD, where there is obvious histological damage to these structures in approximately two thirds of patients. ${ }^{7,8}$ Thus, in patients with T2DM with optimal blood pressure and glycemic control, early preservation of normal glomerular function and use of agents that antagonize the renin-angiotensin system has been a principal approach to reducing the microvascular complications of T2DM including diabetic nephropathy. Thus, progress in the prevention or delay of the progression of diabetic nephropathy has led to the following question: what fundamental cellular pathobiologic processes can be modified to reverse dysfunction before there is cell death, loss of nephron architecture, and organ fibrosis?

\section{Cell signaling and loss of metabolic control of oxidative stress}

All cells in the body have fundamental metabolic functions for energy production and utilization, respiration, protein synthesis, storage, communication, and defense. Understanding of host cell defense mechanisms presumably to guard against infectious agents has led to the concept of "innate immunity." Innate immunity means that each cell has a fundamental set of functions it can operationalize to defend a direct attack in the absence of traditional host defense systems including the traditional components of inflammation: white blood cells, cytokines, antibodies, and complement. Mediated through a variety of conjectured mechanisms (glycated proteins, metabolic signals, insulin, adiponectin, and others), and cytokines, endothelial cells and podocytes can activate a variety of pathways used for innate immunity including intracellular production of reactive oxygen species that, in the absence of an infectious attack, work to promote cellular dysfunction and eventual death. Counter-regulation of this process offers the opportunity to reverse cellular dysfunction and potentially improve organ function. Transcription factor NF-E2-related factor 2, or Nrf-2 is a key regulator of antioxidant, anti-inflammatory and detoxification pathways within cells - presumably endothelial cells and podocytes (Figure 1). ${ }^{9-13}$ In T2DM, Nrf-2 is modestly upregulated, presumably in response to the oxidative stress environment with cells. KEAP-1 (Kelch-like ECH-associated protein 1) represses the function of Nrf-2 and contributes to a regulatory balance over hundreds of genes that control oxidation/ antioxidation and detoxification within cells. ${ }^{14,15}$ Bardoxolone methyl (BARD) is a small molecule activator of Nrf-2, which works to push cellular metabolic balance in favor of antioxidation and detoxification and relatively overpowers KEAP-1.

\section{Activation of Nrf-2 by bardoxolone methyl}

A variety of small molecules have been observed to activate Nrf-2. These molecules include sulforaphane derived from the cabbage family (broccoli, watercress, Brussels sprouts, cabbage and cauliflower), diallyl sulfides (from garlic, onion and chives), curcumin (from turmeric), quercetin (from tea, berries, apples and onions), astaxanthin (from krill, microalgae), resveratrol (from grapes, knotweed), and caffeic acid phenethyl ester (found in bee hives). ${ }^{16}$ Of note, gold has also been shown to induce Nrf-2, and thus, may derive its anti-inflammatory properties from this mechanism. Most of the Nrf-2 activators have been shown to have some modest anti-inflammatory or antioxidant effects. Thus, the rationale for a powerful Nrf-2 activator such as BARD is supported from a broad base of molecular research. Originally tested as an anticancer agent, BARD was found to be protective against cisplatin-induced renal toxicity and improve renal filtration function in animals. ${ }^{17}$ Others had found that induction of Nrf-2 by other methods also appeared to be renally protective by enhancing the cytoprotective antioxidant function of normal cells. ${ }^{18}$ Thus, BARD was brought forward as a possible agent in the use of T2DM CKD where there is considerable evidence for loss of control over oxidative and inflammatory 


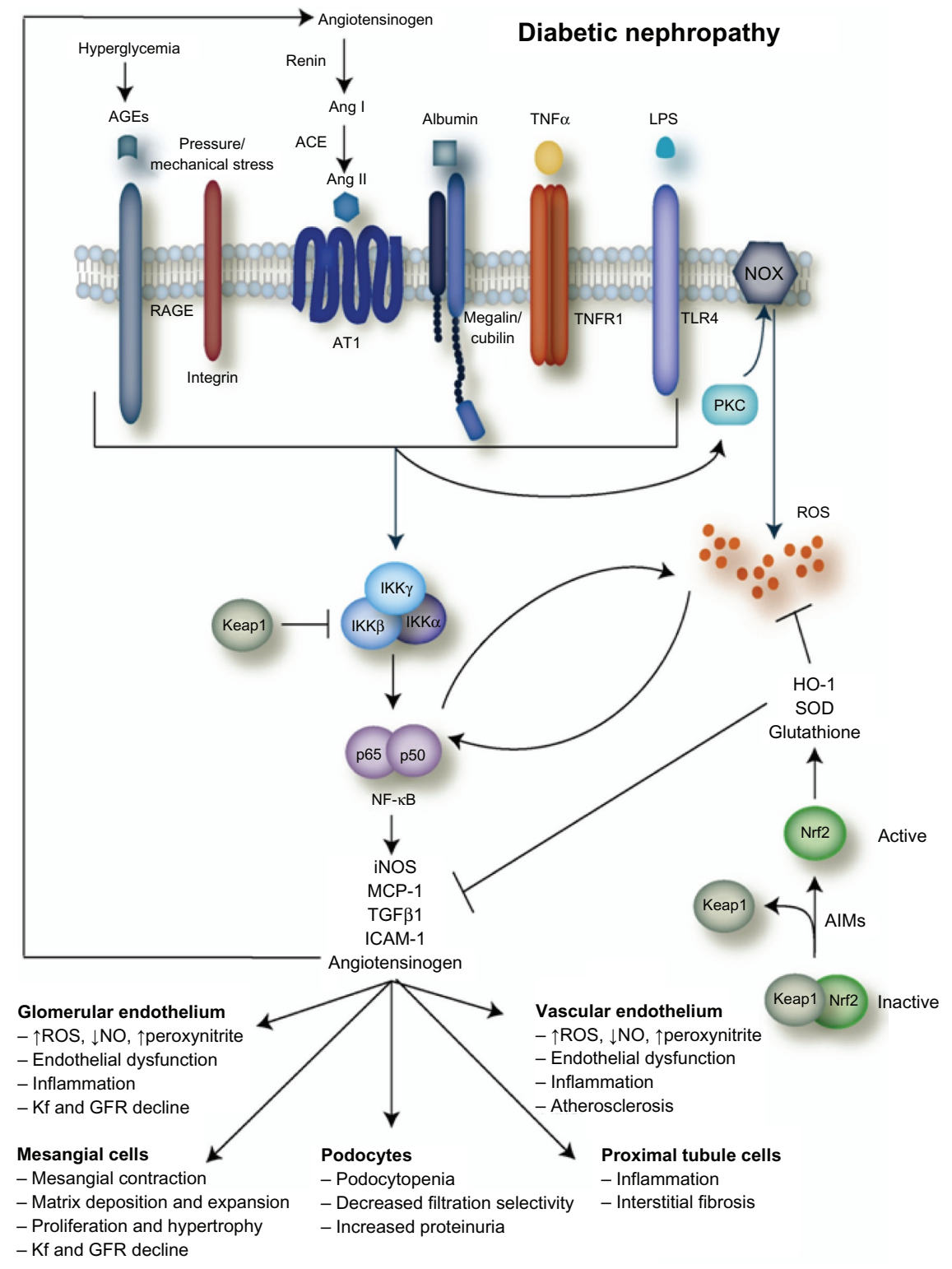

Figure I Proposed mechanisms of action of BARD on the kidney.

Adapted with permission from Ma R, Bumeister R, Stidham RD, et al, editors. Bardoxolone methyl (BARD) inhibits inflammatory signaling in cultured mesangial cells. Proceedings of the National Kidney Foundation Spring Clinical Meetings; April 13-17, 20I0; Lake Buena Vista, FL. ${ }^{20}$

Abbreviations: AGE, advanced glycation end-product; ACE, angiotensin converting enzyme; AT, angiotensin; TNF, tumor necrosis factor; TNFR, tumor necrosis factor receptor; LPS, lipopolysaccharide; TLR, toll-like receptor; NOX, NADPH oxidase; PKC, protein kinase C; IKK, IKB kinase; KEAP, Kelch-like ECH-associated protein I; HO, heme oxygenase; ROS, reactive oxygen species; SOD, superoxide dismutase; NF, nuclear factor; NOS, nitric oxide synthase; Nrf, nuclear regulatory factor; MCP, monocyte chemoattractant protein; TGF, transforming growth factor; ICAM, intracellular adhesion molecule; NO, nitric oxide; GFR, glomerular filtration rate.

processes within vascular and glomerular endothelial cells, podocytes, mesangial cells, and proximal tubules. ${ }^{19,20}$

\section{Clinical observations with bardoxolone methyl}

The majority of studies evaluating BARD in humans are in abstract form and presented in Table 1. Because transcription factor-kappa B and signal transducer and activator of transcription 3 are activated in many tumors and promote proliferation, angiogenesis, metastasis, and tumor survival,
Hong and coworkers intended to leverage the KEAP-1 binding and Nrf-2 inhibition with BARD $900 \mathrm{mg}$ per oral four times daily (po qd) as part of a 21 day/28 cycle treatment of multidrug chemotherapy in patients with a variety of primary cancers (melanoma, renal, thyroid, and others) for up to 12 months. ${ }^{21}$ Bardoxolone methyl appeared to reduce tumor cell variability, signal transducer and activator of transcription 3, and transcription factor-kappa B expression by immunohistochemistry in subjects with repeated biopsies. In addition, the drug was well tolerated in these patients 


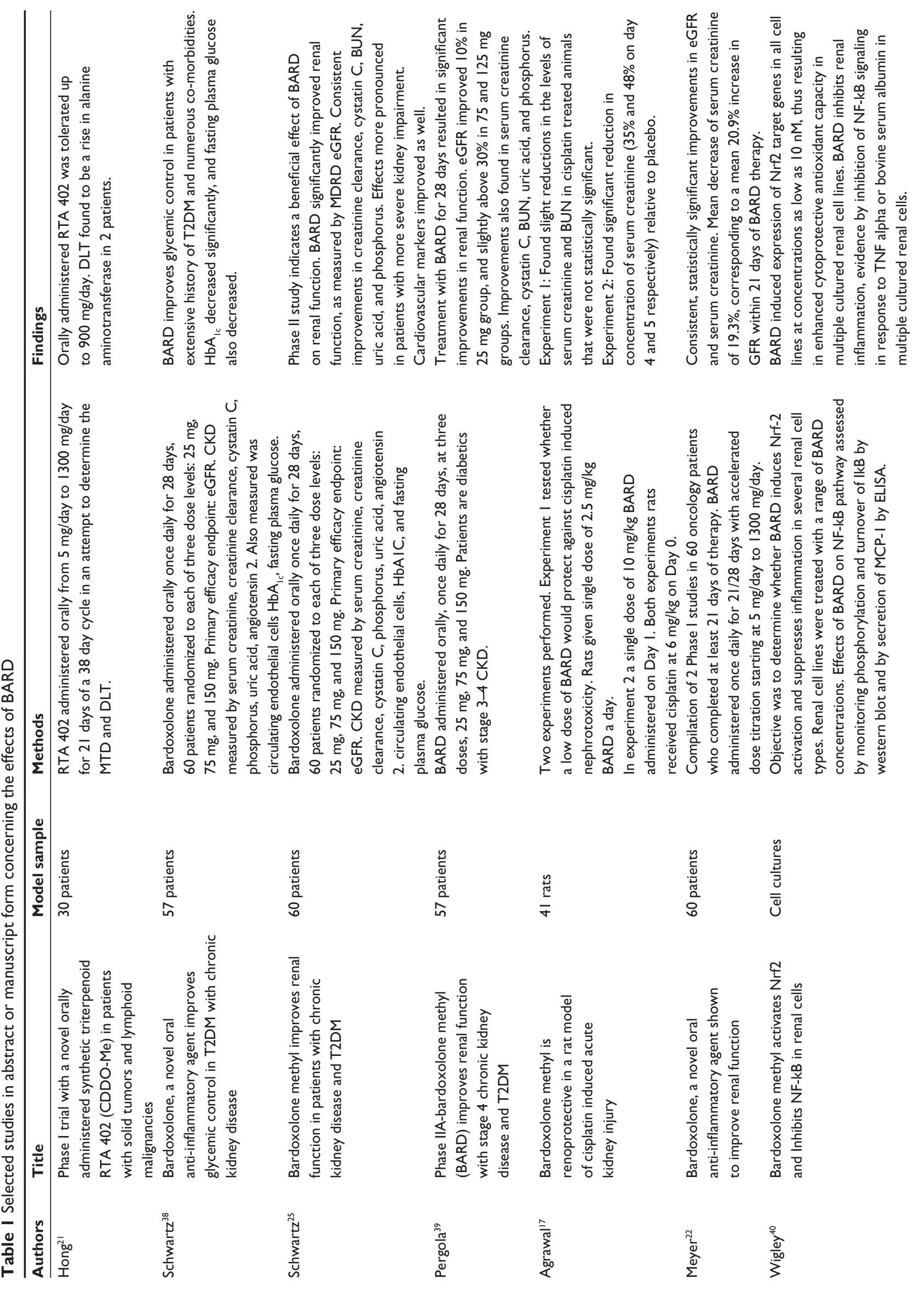



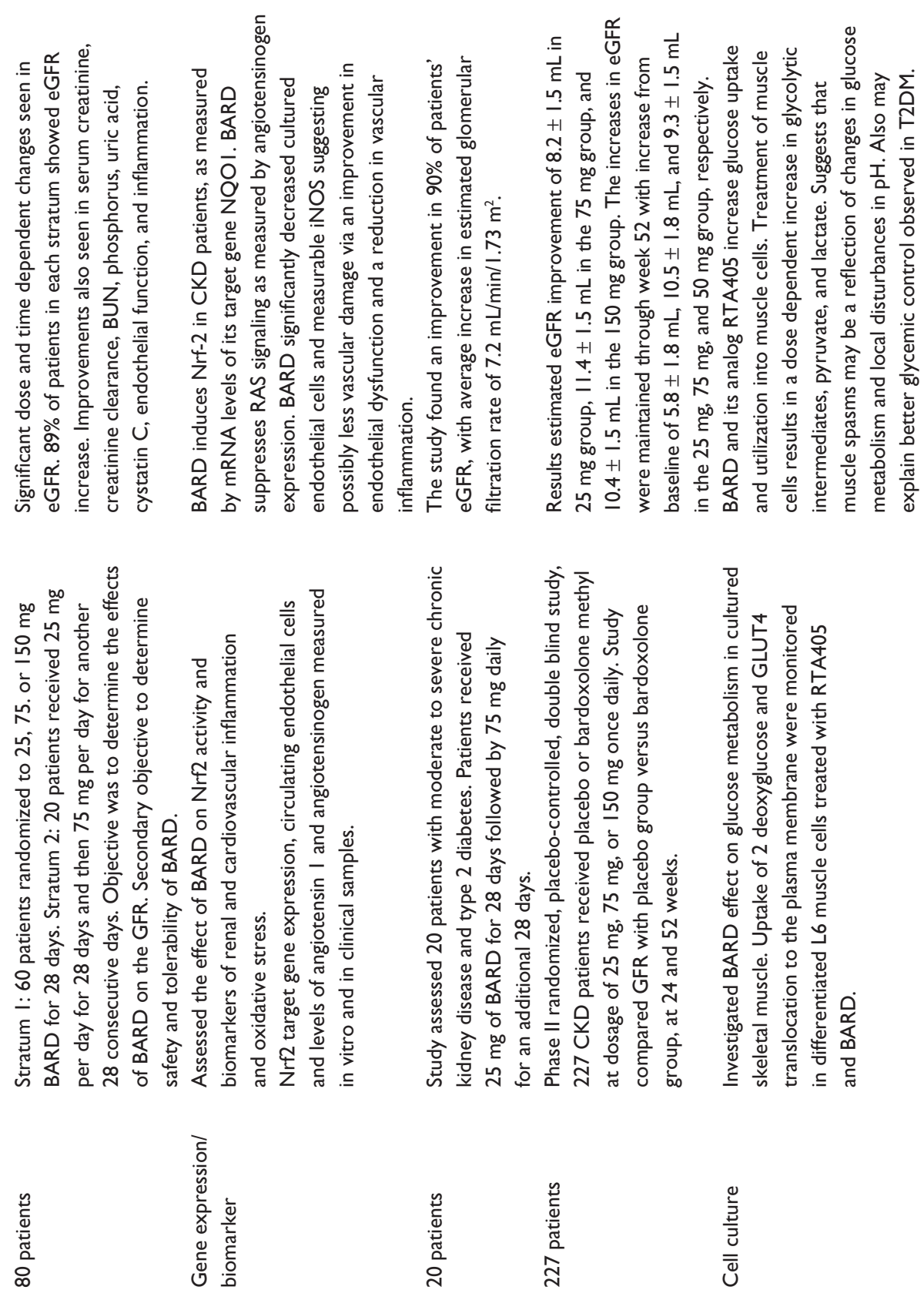

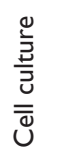
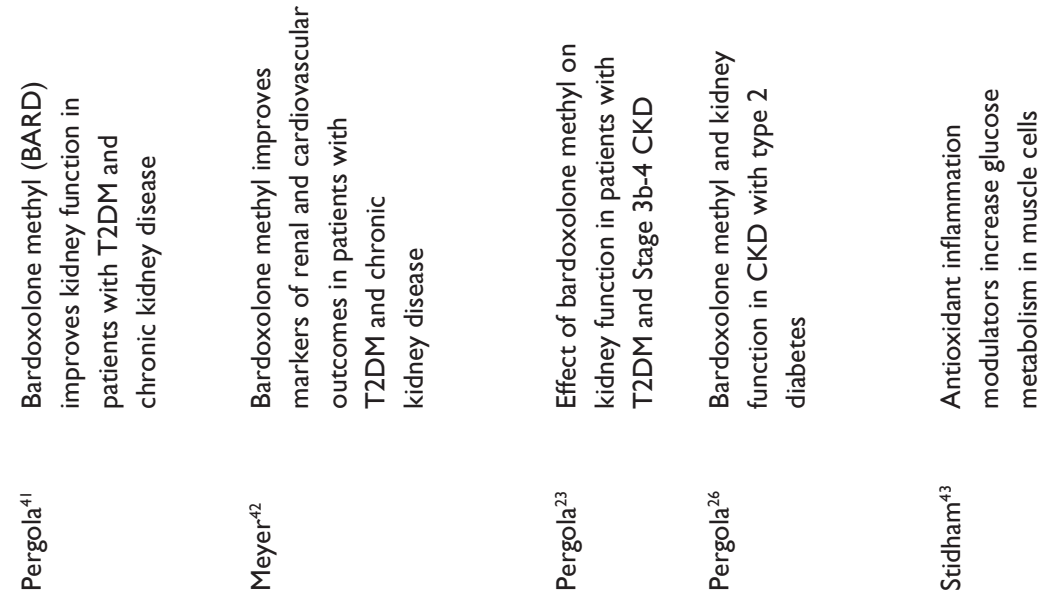

疍

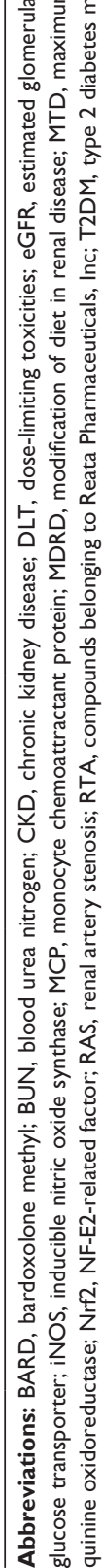


with advanced tumor burden. The first paper incorporating these patients as well as another group of Phase I subjects was presented in 2009 and demonstrated within 21 days, in patients with baseline serum creatinine levels and estimated glomerular filtration rate (eGFR) of $1.00 \mathrm{mg} / \mathrm{dL}$ and $79.9 \mathrm{~mL} / \mathrm{min} / 1.73 \mathrm{~m}^{2}$, respectively, 82\% (49/60) of BARD-treated patients experienced a mean decrease in serum creatinine levels of $19.3 \%$, corresponding to a mean $20.9 \%$ increase in eGFR. Of note, the eGFR improvements were more pronounced in a subset $(n=13)$ of patients with established CKD (eGFR $<60 \mathrm{~mL} / \mathrm{min} / 1.73 \mathrm{~m}^{2}$ at baseline). In these patients the eGFR increased a mean of $27.6 \%$. The changes in eGFR were sustained over six months, supported by decreases in blood urea nitrogen, and unrelated to changes in body weight. ${ }^{22}$ This observation made in 2008 by Meyer and coworkers was the springboard for a new direction in product development and a Phase II trial of BARD in patients with diabetic nephropathy.

Pergola and colleagues in April 2011 published the first prospective, open-label multicenter study of BARD $25 \mathrm{mg}$ po qd for 28 days and titrated to $75 \mathrm{mg}$ for an additional 28 days in 20 patients with diabetic nephropathy (Figure 2). ${ }^{23}$ The mean age of subjects was 64 years, average duration of T2DM was 16 years, mean eGFR was $30.3 \mathrm{~mL} / \mathrm{min} / 1.73 \mathrm{~m}^{2}$, and $45 \%$ had an albumin:creatinine ratio in the urine $>$ $300 \mathrm{mg} / \mathrm{g}$. At 56 weeks, the mean and median eGFR rose by 7.2 and $5.5 \mathrm{~mL} / \mathrm{kg} / 1.73 \mathrm{~m}^{2}$ respectively, $P<0.0001$.
Those with the lowest baseline eGFR values tended to have the greatest increases with BARD (Figure 1). Of note, there was a minor increase in 24 hour urine creatinine $(1272.1 \pm 452.7$ to $1333.5 \pm 440.6, P=0.47$ ) and an increase in a urinary marker of renal damage, neutrophil gelatinase-associated lipocalin (NGAL) from $79.0 \pm 98.8$ to $93.2 \pm 112.5, P=0.93$. Thus, there were questions over real changes in renal filtration function and whether or not BARD influenced constitutive production of NGAL, a marker of chronic renal damage in diabetic nephropathy. ${ }^{24}$ The most common adverse effect reported was skeletal muscle spasms in $35 \%$ of subjects. Of note, Schwartz and colleagues observed that glycemic control improved in patients with T2DM as given in Table $1 .{ }^{25}$

These observations were the basis for a Phase II doubleblind placebo controlled trial of BARD at three doses $(25,75,150 \mathrm{mg})$ versus placebo in $227 \mathrm{~T} 2 \mathrm{DM}$ patients with an eGFR 20 to $45 \mathrm{~mL} / \mathrm{min} / 1.73 \mathrm{~m}^{2}$ (stages 3 and $4 \mathrm{CKD)}{ }^{26}$ The primary and secondary outcomes were the change from baseline in eGFR at 24 and 52 weeks, respectively. The mean eGFR was $32 \mathrm{~mL} / \mathrm{min} / 1.73 \mathrm{~m}^{2}$. The albumin:creatinine ratio was less than 30 (normoalbuminuria) in $37 \%$ of patients, 30 to 300 (microalbuminuria) in 29\%, and more than 300 (macroalbuminuria) in 34\%. The rise in eGFR for each group treated with BARD peaked at 12 weeks. The greatest mean increase in eGFR was observed in the BARD $75 \mathrm{mg}$ group, $11.4 \mathrm{~mL} / \mathrm{min} / 1.73 \mathrm{~m}^{2}$ from a baseline of $33.0(36 \%$ increase). Increases in all three groups were sustained out

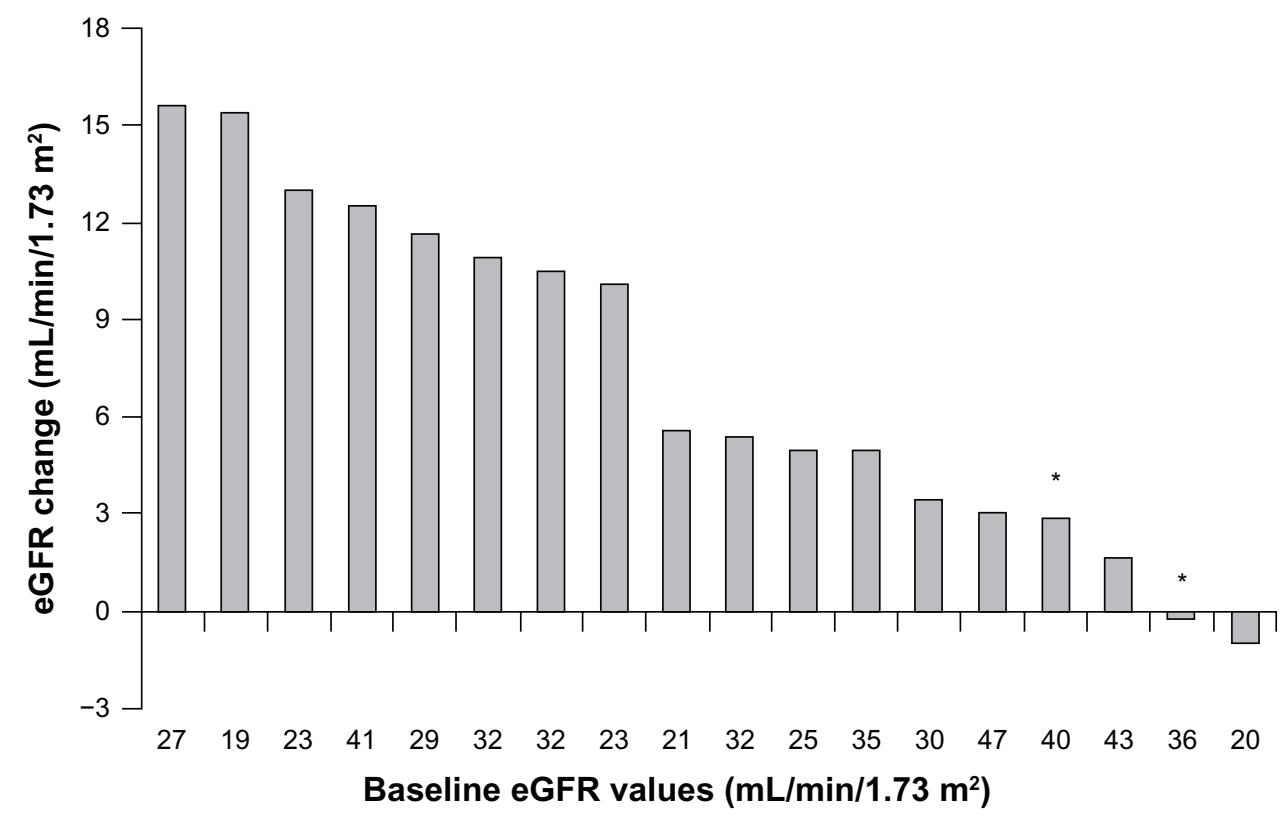

Figure 2 Larger improvements in renal function human subjects with lower eGFR.

Copyright @ 20I I, Karger AG. Reproduced with permission from Pergola PE, Krauth M, Huff JW, et al. Effect of bardoxolone methyl on kidney function in patients with T2D and Stage 3b-4 CKD. Am J Nephrol. 20I I;33(5):469-476. ${ }^{23}$

Note: Asterisks indicate patients who did not undergo successful dose escalation to $75 \mathrm{mg} /$ day. 
to 52 weeks (Figure 3). Again the most common adverse event reported with BARD was muscle spasms which occurred in $42 \%$ of the $25 \mathrm{mg}$ group, $61 \%$ of the $75 \mathrm{mg}$ group, and $59 \%$ of the $150-\mathrm{mg}$ group. The muscle spasms were most common in the calf muscles of the lower leg. Additionally, hypomagnesemia occurred in $21 \%, 25 \%$, and $32 \%$ of the BARD 25,75 , and $150 \mathrm{mg}$ groups, respectively. A total of 18 patients $(11 \%)$ had transient alanine aminotransferase elevation of more than three times the upper limit of the normal range, but there was evidence of cholestasis or hepatic failure.

The synthesis of clinical information to date with BARD on the kidneys is mixed. While there is improvement in eGFR, elimination of urinary creatinine was not impressive and there was no salutary signal seen with NGAL, a reliable proteomic measure of renal health both in chronic and acute kidney disease. ${ }^{27}$ There have been no studies on the influence of BARD on microalbuminuria or proteinuria. Because BARD has been associated with a reduction in body weight, of which $25 \%$ is usually muscle mass, it is possible that a portion of the improvement in eGFR is attributable to a reduction in creatinine production. ${ }^{28}$ While BARD may improve renal filtration by a variety of effects on the filtration barrier, it is possible that it also has a hemodynamic effect and result in elevation of intraglomerular pressure. As a result of either mechanism, there is considerable translational evidence that increasing glomerular filtration in the setting of a reduced nephron mass is due to hyperfiltration of the remaining nephrons. Hyperfiltration, while in the short-term lowers serum creatinine, ultimately leads to greater losses of nephrons and ultimately a hastened progression of kidney disease in many models. ${ }^{29}$

\section{Potential effects of bardoxolone methyl and the cardiomyocyte}

As with potential salutary effects on the podocyte and other participating line lines involved in glomerular filtration, it is possible that BARD may impact the myocardium. The consistent effect of BARD on skeletal muscle suggests it influences either transit of electrolytes across the cell membrane and sarcoplasmic reticulum or contractile elements more directly as a result of its many influences on the nucleus. Lower blood magnesium levels are common with BARD and it is possible that a relative deficiency of cellular and plasma magnesium could lead to myocyte and dysfunction and arrhythmias. ${ }^{30,31}$ In addition, hypomagnesemia has been associated with renal tubular inflammation via activation of nuclear factor kappa beta and a more progressive course to end-stage renal disease in patients with diabetic nephropathy. ${ }^{32,33}$ It has been shown that Nrf-2 upregulates the mRNA, protein, and activity of

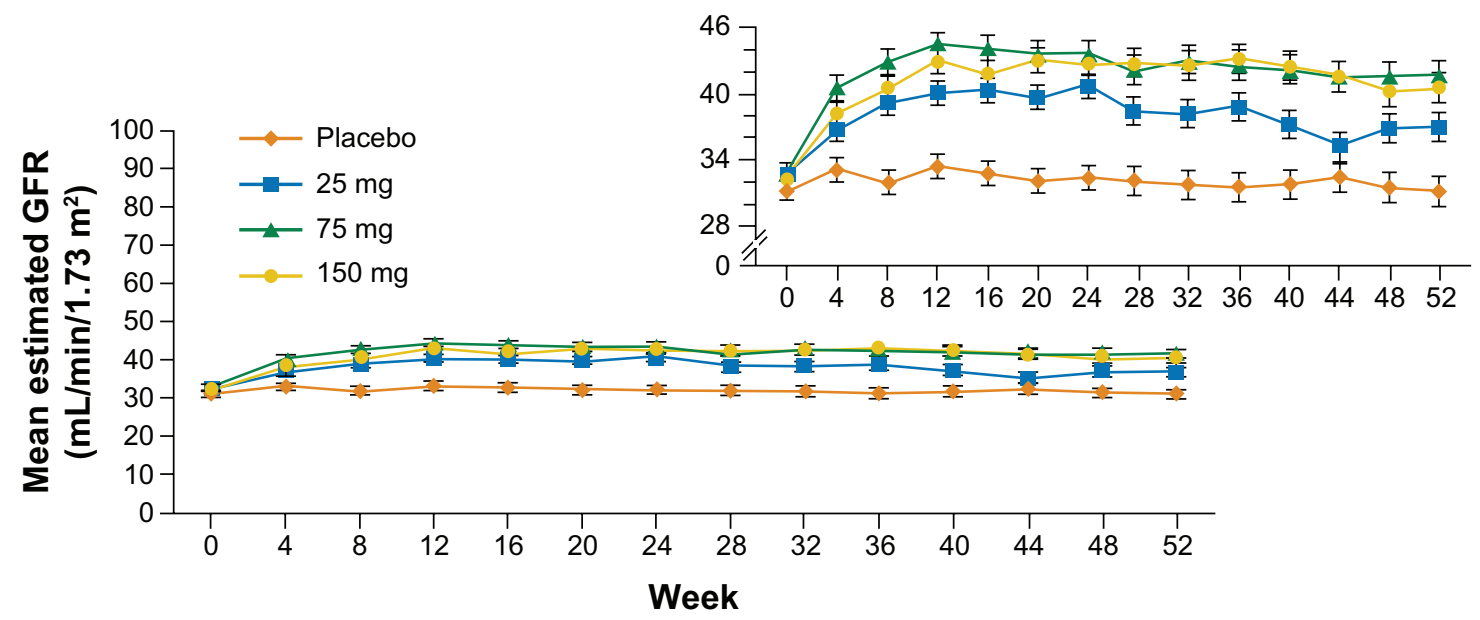

$\begin{array}{lllllllllllllll}\begin{array}{l}\text { No at risk } \\ \text { Placebo }\end{array} & 57 & 56 & 55 & 53 & 54 & 54 & 54 & 53 & 53 & 52 & 53 & 51 & 53 & 52 \\ \begin{array}{l}\text { Bardoxolone } \\ \quad \text { methyl, 25 mg }\end{array} & 57 & 53 & 52 & 52 & 52 & 51 & 51 & 49 & 49 & 47 & 48 & 48 & 48 & 48 \\ \begin{array}{c}\text { Bardoxolone } \\ \quad \text { methyl, } 75 \mathrm{mg}\end{array} & 57 & 55 & 51 & 51 & 53 & 52 & 52 & 51 & 48 & 50 & 50 & 48 & 48 & 48 \\ \begin{array}{c}\text { Bardoxolone } \\ \text { methyl, } 150 \mathrm{mg}\end{array} & 56 & 55 & 55 & 54 & 53 & 52 & 52 & 48 & 48 & 47 & 47 & 46 & 46 & 44\end{array}$

Figure 3 Overall changes in eGFR with three dose levels of BARD.

Copyright $^{\odot} 201$ I, Karger AG. Reproduced with permission from Pergola PE, Krauth M, Huff JW, et al. Effect of bardoxolone methyl on kidney function in patients with T2D and Stage 3b-4 CKD. Am J Nephrol. 20I I;33(5):469-476. ${ }^{23}$ 
the antioxidant enzyme heme-oxygenase-1 as well as mRNA and protein for nuclear respiratory factor-1 (Nrf-1) in cardiac myocytes ${ }^{34}$ Heme-oxygenase- 1 directs a feedback loop involving the generation of intracellular carbon monoxide and hydrogen peroxide to amplify the expression of the gene for Nrf-1 and the accumulation of nuclear Nrf-1 protein leads to gene activation for mitochondrial biogenesis, which opposes apoptosis and necrosis in experimental models anthracyclineinduced cardiac injury. However, mitochondrial biogenesis can also be induced by peroxisome proliferator-activated receptor (PPAR) gamma co-activator-1 alpha. ${ }^{35}$

In both animal models and clinical trials, stimulation of PPAR-gamma therapeutically over time leads to salt and water retention and heart failure. ${ }^{36}$ Changes in myocyte mitochondrial biogenesis may link future observations with BARD in both the skeletal muscles and the heart. Thus, a biphasic response can be seen with early improvement and later decline reflected by the increase and later decrease in the number of mitochondria within the cells. ${ }^{37}$ We recognize this line of deduction concerning intracellular processes and the effects of BARD is highly speculative at this point, however, if blood pressure is found to increase or if impaired left ventricular function is observed in future trials with BARD, this chain of logic should be considered. In summary, BARD could induce overall favorable effects on the heart via its improvement in eGFR; however, at a cellular and tissue level, chronic exposure to BARD theoretically could lead to adverse changes that contribute either directly or indirectly to cardiomyopathy, pump failure, and arrhythmias.

\section{Summary}

This review has summarized the cellular and clinical effects of BARD to date as they relate to the heart and kidneys. While there is great hope for an agent that improves renal filtration function, we reserve caution with respect to adverse organ toxicity over time to both the glomerulus and the myocardium. Only large, prospective randomized trials with carefully collected and adjudicated clinical outcomes will inform the research community on the therapeutic risks and benefits of this important new agent.

\section{Disclosure}

The authors report no conflicts of interest in this work.

\section{References}

1. McCullough PA, Bakris GL, Owen WF Jr, Klassen PS, Califf RM. Slowing the progression of diabetic nephropathy and its cardiovascular consequences. Am Heart J. 2004;148(2):243-251.
2. Ronco C, McCullough PA, Anker SD, et al. Cardiorenal syndromes: an executive summary from the consensus conference of the Acute Dialysis Quality Initiative (ADQI). Contrib Nephrol. 2010;165:54-67.

3. McCullough PA, Ahmad A. Cardiorenal syndromes. World J Cardiol. 2011;3(1):1-9.

4. Agrawal V, Kizilbash SH, McCullough PA. New therapeutic agents for diabetic kidney disease. Therapy. 2008;5(4):553-575.

5. McCullough PA. Prevention of cardiorenal syndromes. Contrib Nephrol. 2010;165:101-111.

6. Haraldsson B, Jeansson M. Glomerular filtration barrier. Curr Opin Nephrol Hypertens. 2009;18(4):331-335.

7. Satchell SC, Tooke JE. What is the mechanism of microalbuminuria in diabetes: a role for the glomerular endothelium? Diabetologia. 2008;51(5):714-725.

8. Diez-Sampedro A, Lenz O, Fornoni A. Podocytopathy in diabetes: a metabolic and endocrine disorder. Am J Kidney Dis. 2011;58(4): 637-646.

9. Jones DP. Radical-free biology of oxidative stress. Am J Physiol Cell Physiol. 2008;295(4):C849-C868.

10. Kang KW, Lee SJ, Kim SG. Molecular mechanism of nrf2 activation by oxidative stress. Antioxid Redox Signal. 2005;7(11-12): 1664-1673.

11. Surh YJ, Kundu JK, Na HK. Nrf2 as a master redox switch in turning on the cellular signaling involved in the induction of cytoprotective genes by some chemopreventive phytochemicals. Planta Med. 2008;74(13): $1526-1539$.

12. Nguyen T, Yang CS, Pickett CB. The pathways and molecular mechanisms regulating Nrf2 activation in response to chemical stress. Free Radic Biol Med. 2004;37(4):433-441.

13. Jaiswal AK. Nrf2 signaling in coordinated activation of antioxidant gene expression. Free Radic Biol Med. 2004;36(10):1199-1207.

14. Ungvari Z, Bailey-Downs L, Gautam T, et al. Adaptive induction of NF-E2-related factor-2-driven antioxidant genes in endothelial cells in response to hyperglycemia. Am J Physiol Heart Circ Physiol. 2011; 300(4):H1133-H1140.

15. Okouchi M, Okayama N, Alexander JS, Aw TY. NRF2-dependent glutamate-L-cysteine ligase catalytic subunit expression mediates insulin protection against hyperglycemia- induced brain endothelial cell apoptosis. Curr Neurovasc Res. 2006;3(4):249-261.

16. Thomas MC. Bardoxolone: augmenting the Yin in chronic kidney disease. Diab Vasc Dis Res. 2011;8(4):303-304.

17. Agrawal A, Chen B, Liby KT, Meyer C, editors. Bardoxolone methyl is renoprotective in a rat model of cisplatin induced acute kidney injury. Proceedings of the 42nd Annual American Society of Nephrology Renal Week; October 27-November 1, 2009; San Diego, CA. Irving, TX: Reata Pharmaceuticals.

18. Park HM, Cho JM, Lee HR, Shim GS, Kwak MK. Renal protection by 3H-1,2-dithiole-3-thione against cisplatin through the Nrf2-antioxidant pathway. Biochem Pharmacol. 2008;76(5):597-607.

19. Gupta A, Khaira A. Bardoxolone methyl: a targeted antioxidant. Ren Fail. 2011;33(10):1051.

20. Ma R, Bumeister R, Stidham RD, et al, editors. Bardoxolone methyl (BARD) inhibits inflammatory signaling in cultured mesangial cells. Proceedings of the National Kidney Foundation Spring Clinical Meetings; April 13-17, 2010; Lake Buena Vista, FL.

21. Hong DS, Kurzrock R, Supko JG, et al. Phase I trial with a novel orally administered synthetic triterpenoid RTA 402 (CDDO-Me) in patients with solid tumors and lymphoid malignancies. European Organisation for Research and Treatment of Cancer, the National Cancer Institute, and the American Association for Cancer Research, the 2007 Symposium on Molecular Targets and Cancer Therapeutics (Abstract).

22. Meyer C. Bardoxolone, A Novel Oral Anti-Inflammatory Agent Shown to Improve Renal Function. National Kidney Foundation Spring Clinical Meeting 2009 (Abstract).

23. Pergola PE, Krauth M, Huff JW, et al. Effect of bardoxolone methyl on kidney function in patients with T2D and Stage 3b-4 CKD. Am J Nephrol. 2011;33(5):469-476. 
24. Fu WJ, Li BL, Wang SB, et al. Changes of the tubular markers in type 2 diabetes mellitus with glomerular hyperfiltration. Diabetes Res Clin Pract. 2012;95(1):105-109.

25. Schwartz S, Denham D, Hurwitz C, Meyer C, Pergola P. Bardoxolone Methyl Improves Renal Function in Patients with Chronic Kidney Disease and Type 2 Diabetes Mellitus. American Society of Clinical Oncology 2008 (Abstract).

26. Pergola PE, Raskin P, Toto RD, et al. Bardoxolone methyl and kidney function in CKD with type 2 diabetes. $N$ Engl J Med. 2011;365(4): 327-336.

27. Fassett RG, Venuthurupalli SK, Gobe GC, Coombes JS, Cooper MA, Hoy WE. Biomarkers in chronic kidney disease: a review. Kidney Int. 2011;80(8):806-821.

28. Zalesin KC, Franklin BA, Lillystone MA, et al. Differential loss of fat and lean mass in the morbidly obese after bariatric surgery. Metab Syndr Relat Disord. 2010;8(1):15-20.

29. Kriz W, LeHir M. Pathways to nephron loss starting from glomerular diseases-insights from animal models. Kidney Int. 2005;67(2): 404-419.

30. Borkowski BJ, Cheema Y, Shahbaz AU, Bhattacharya SK, Weber KT. Cation dyshomeostasis and cardiomyocyte necrosis: the Fleckenstein hypothesis revisited. Eur Heart J. 2011;32(15):1846-1853.

31. Chakraborti S, Chakraborti T, Mandal M, Mandal A, Das S, Ghosh S. Protective role of magnesium in cardiovascular diseases: a review. Mol Cell Biochem. 2002;238(1-2):163-179.

32. Asai T, Nakatani T, Tamada S, et al. Activation of transcription factors AP-1 and NF-kappaB in chronic cyclosporine A nephrotoxicity: role in beneficial effects of magnesium supplementation. Transplantation. 2003;75(7):1040-1044.

33. Sakaguchi Y, Shoji T, Hayashi T, et al. Hypomagnesemia in type 2 diabetic nephropathy: a novel predictor of end-stage renal disease. Diabetes Care. April 12, 2012. [Epub ahead of print.]

34. Piantadosi CA, Carraway MS, Babiker A, Suliman HB. Heme oxygenase-1 regulates cardiac mitochondrial biogenesis via Nrf2-mediated transcriptional control of nuclear respiratory factor-1. Circ Res. 2008;103(11):1232-1240.
35. Suliman HB, Carraway MS, Tatro LG, Piantadosi CA. A new activating role for $\mathrm{CO}$ in cardiac mitochondrial biogenesis. J Cell Sci. 2007; 120(Pt 2):299-308.

36. Blasi ER, Heyen J, Hemkens M, McHarg A, Ecelbarger CM, Tiwari S. Effects of Chronic PPAR-Agonist Treatment on Cardiac Structure and Function, Blood Pressure, and Kidney in Healthy Sprague-Dawley Rats. PPAR Res. 2009;2009:237865.

37. Schrepper A, Schwarzer M, Schöpe M, Amorim PA, Doenst T. Biphasic response of skeletal muscle mitochondria to chronic cardiac pressure overload - role of respiratory chain complex activity. J Mol Cell Cardiol. 2012;52(1):125-135.

38. Schwartz S, Denham D, Hurwitz C, Meyer C, Pergola P. Bardoxolone, a Novel Oral Anti-Inflammatory Agent Improves Glycemic Control in Type 2 Diabetics with Chronic Kidney Disease. American Society of Clinical Oncology 2008 (Abstract).

39. Pergola PE, Schwartz S, Denham D, et al. Bardoxolone Methyl Improves Renal Function with Stage 4 Chronic Kidney Disease and Type 2 Diabetes Mellitus. World Congress of Nephrology 2009 (Abstract).

40. Wigley WC, Bumeister R, Stidham RD, Kambuj PA, Laidlaw J, Ferguson DA. Bardoxolone Methyl (BARD) Activates Nrf2 and Inhibits NF- $\kappa \mathrm{B}$ in Renal Cells. American Society of Nephrology Renal Week 2009 (Abstract).

41. Pergola PE, Schwartz S, Craig HA, Meyer CJ. Bardoxolone Methyl Improves Kidney Function in Patients with Type 2 Diabetes and Chronic Kidney Disease. American society of Nephrology Renal Week 2009 (Abstract).

42. Meyer CJ, Ferguson DA, Laidlaw J, et al. Bardoxolone Methyl Improves Markers of Renal and Cardiovascular Outcomes in Patients with Type 2 Diabetes and Chronic Kidney Disease. American Society of Nephrology Renal Week 2009 (Abstract).

43. Stidham RD, Palaia T, Bumeister R, Ferguson DA, Wigley CW, Ragolia L. Antioxidant Inflammation Modulators Increase Glucose Metabolism in Muscle Cells. American Society of Nephrology Renal Week 2011 (Abstract).

\section{Publish your work in this journal}

Drug Design, Development and Therapy is an international, peerreviewed open-access journal that spans the spectrum of drug design and development through to clinical applications. Clinical outcomes, patient safety, and programs for the development and effective, safe, and sustained use of medicines are a feature of the journal, which

\section{Dovepress}

has also been accepted for indexing on PubMed Central. The manuscript management system is completely online and includes a very quick and fair peer-review system, which is all easy to use. Visit http://www.dovepress.com/testimonials.php to read real quotes from published authors. 